\title{
A ÉTICA NA ERA DA BIOTECNOLOGIA: uma reflexão filosófica a partir dos conceitos "Responsabilidade" e "Vida" na filosofia de Hans Jonas
}

Ethics in the age of biotechnology: a philosophical reflection from the concepts of "responsibility" and "life" in the philosophy of Hans Jonas

Rayane Ferreira dos Santos ${ }^{1}$

RESUMO: Jonas viveu em uma época dominada por guerras, nazismo, pelo triunfo da sociedade tecnológica, e por crises ambientais, tudo isso levou o filósofo a refletir sobre a vida e a natureza e como as guerras e a tecnologia ficavam em relação à vida. Ele percebeu que a visão sobre a natureza estava abalada, e não era vista como algo a ser resolvida no imediato. Vendo que as teorias de sua época não estavam sendo capazes de resolver os problemas imediatamente e colocavam em cheque o futuro, ele começou suas pesquisas, estudos e suas reflexões. A partir de sua inquietações, Hans Jonas publica "O Princípio Responsabilidade: ensaio para uma ética da civilização tecnológica", buscando fazer uma relação entre homem, natureza e tecnologia. Em suas reflexões, Jonas busca, de forma clara, demonstrar os benefícios e os malefícios oriundos da nova realidade da tecnologia, demonstrando também as responsabilidades de todos perante essa nova realidade, que mexe com o presente e o futuro da humanidade.

PALAVRAS-CHAVE: Hans Jonas; Vida; Tecnologia; Biologia.

RESUMO: Jonas lived in an era dominated by war, Nazism, the triumph of technological society, and environmental crises, all this led the philosopher to reflect about life and nature and how wars and technology were affecting negatively the phenomenon of life. He realized that the view of nature was shaken by Modernity, and it was not anymore seen as something to be resolved immediately. Seeing that the theories of his time were not being able to solve problems immediately and put in check the future, he began his research, studies and their reflections. From his concerns, Hans Jonas publishes "The Responsibility Principle: Test for an ethics of technological civilization", seeking to make a relationship between man, nature and technology. In his reflections, Jonas seeks to clearly demonstrate the benefits and detriments arising from the new reality technology, also demonstrating the responsibilities of all before this new reality that stirs the present and the future of humanity.

PALAVRAS-CHAVE: Hans Jonas; Life; Technology; Biology.

\footnotetext{
${ }^{1}$ Aluna do ensino médio integrado no Instituto federal de Educação, Ciência e Tecnologia do Maranhão. Campus Caxias. Bolsista de Iniciação Científica - PIBIC JR. Orientada pela professora Me. Hellen Lopes.
} 


\section{INTRODUÇÃO}

Vivemos a era das tecnologias, isso seria satisfatório se o uso feito da técnica estivesse relacionado somente ao bem estar da humanidade, à resolução de problemas antes insolúveis como a cura para determinadas doenças, entre outros. Porém, o uso da tecnologia, às vezes mascarada em benfeitorias, também são utilizadas para experimentos nada altruístas, "a ética que Hans Jonas aborda como ética da responsabilidade é uma área do conhecimento que emerge questões relacionadas à bioética"”. (BATTESTIN e GHIGGI, 2010, p,73).

Partindo dessa reflexão, o nosso trabalho teve como objetivo analisar, a partir da obra do filósofo alemão Hans Jonas, suas preocupações para as novas sociedades predominantemente tecnológicas. Preocupação pautada no uso indiscriminado da técnica. Sua preocupação inicial é com as gerações futuras. O nosso modo de tomar decisões, de agir de um modo geral não é mais o mesmo de séculos anteriores, assim, as regras que antes cabiam hoje, não são mais satisfatórias. Jonas nos mostra que, pontando, a necessidade de pensarmos em novos valore para essa nova sociedade,

Quando nos perguntamos que valores de ontem são utilizáveis e continuarão sendo importantes para o mundo de amanhã, estamos perguntando ao mesmo tempo quais envelheceram e, talvez, quais perderam importância - mas também, vice-versa, quais novos valores um novo amanhã trará à tona. Teremos desse modo, se não um saber, ao menos alguma ideia de como será o mundo de amanhã; pressupondo antes de tudo e, sobretudo, que será diferente do de hoje. (JONAS, 2013, p, 63).

Nesse caso, Jonas está voltado para um novo agir, uma nova ética pautada na responsabilidade dos humanos com seu ambiente natural, uma ética da responsabilidade dos contemporâneos para com as gerações vindouras.

Conter tal progresso deveria ser visto como nada mais do que uma precaução inteligente, acompanhada de uma simples decência em relação aos nossos descendentes. $\mathrm{O}$ medo que faz parte da responsabilidade não é aquele que nos aconselha a não agir, mas aquele que nos convida a agir. Trata-se de um medo que tem a ver com o objeto da responsabilidade. Trata-se de assumir a responsabilidade pelo futuro do homem (JONAS, 2006, p. 353).

Assim segue nossa reflexão guiada pelo pensamento e pela preocupação de Jonas. É necessário pensarmos a técnica por todos os seus vieses para todos os seus usos, só assim

\footnotetext{
${ }^{1}$ Hans Jonas buscou aproximar a Ética Filosófica com a Ética prática, ou seja, os valores humanos e o conhecimento biológico.
} 
conseguiremos constituir uma ética que tenha como princípio a Responsabilidade para com o futuro.

\section{O PRINCÍPIO RESPONSABIBLIDADE PARA UMA SOCIEDADE TECNOLÓGICA}

Até a época medieval, a Natureza afigurou-se como duradoura e permanente, que sofria ciclos e alterações, mas era sempre capaz de se recuperar sem dificuldade, inclusive das pequenas agressões que o homem lhe causava com as suas localizadas intervenções.

Esta concepção mudou radicalmente com a ciência moderna e a técnica dela derivada. O homem passou de fato, a ser uma ameaça para a continuidade da vida na terra. Não só pode acabar com a sua existência como também pode alterar a essência do homem e desfigurá-la mediante diversas manipulações. "Sob o signo da tecnologia, a ética tem a ver com ações de um alcance causal que carece de precedentes (...). Tudo isso coloca a responsabilidade no centro da ética”. (JONAS, 2006, p. 16-17).

A maioria das éticas antigas não responde plenamente aos desafios do presente. Torna-se necessária uma nova ética: uma ética orientada para o futuro. A mesma não significa que seja praticada apenas "aos homens de amanhã". Ao contrário, o dever de cuidar do futuro e de responsabilidade dos homens do presente. Responsabilidades estão que estão para além do antropocêntrico, como nos mostra Jonas,

Ao ultrapassar o horizonte da vizinhança espaço-temporal, esse alcance ampliado do poder humano rompe o monopólio antropocêntrico da maioria dos sistemas éticos anteriores, sejam religiosos ou seculares. Era sempre o bem bumano que deveria fomentado; os interesses e direitos dos congêneres, respeitados; os maus feitos a eles, corrigidos; e seus sofrimentos, aliviados. $\mathrm{O}$ objeto do dever humano eram os homens, no caso extremo, a humanidade, e nada mais neste mundo. (Usualmente o horizonte ético tinha limites muito mais restritos, como, por exemplo, o "ama ao teu próximo"). Nada disso perdeu sua força vinculante. Mas agora a biosfera inteira do planeta, com toda sua abundância de espécies, em sua recém-revelada vulnerabilidade perante as excessivas intervenções do homem, reivindica sua parcela do respeito que se deve a tudo o que é um fim em si mesmo, quer dizer, a todos os viventes. (JONAS, 2013, p.55).

E foi através dessa problemática que Hans Jonas dedicou-se a uma filosofia baseada no Princípio Responsabilidade, presentando um novo paradigma ético, vocacionado para o nível coletivo e para ação dos agentes político-sociais, grandes responsáveis e contribuintes para "regrar e orientar a ação humana", "uma ética atual que se preocupa com o futuro, que pretende proteger os nossos descendentes das consequências das nossas ações presentes". 
O enorme impacto do Princípio Responsabilidade não se deve somente a sua fundamentação filosófica, mas ao sentimento geral, que até então os mais atentos observadores poderão permitir cada vez menos de que algo poderia ir mal para a humanidade, inclusive o tempo poderia estar em posição no marco de crescimento exagerado e crescente das interferências técnicas sobre a natureza, de pôr em jogo a própria existência. Entretanto, se havia comentado que era evidente a vinda da chuva ácida, o efeito estufa, a poluição dos rios e muitos outros efeitos perigosos, fomos pegos de cheio na destruição de nossa biosfera (JONAS, 2005, p. 352-353).

A sociedade em que Jonas viveu presenciou o avanço da evolução tecnológica, assim, nasceu o Princípio Responsabilidade, em que o filósofo enfatiza a necessidade de uma nova ética, a fim de frear os poderes da tecnologia e nortear o seu desenvolvimento e a sua utilização. Diante desta inovadora visão, o filósofo reforça que, o que está em jogo, é a vida de tudo e de todos, isto é, a biosfera, o ecossistema e todos os recursos oriundos da natureza devem ser protegidos hoje, para que as gerações futuras possam usufruir dos inúmeros e insubstituíveis benefícios proporcionados, como a água, o ar, o solo e o alimento, que fazem com que todas as espécies se perpetuem na Terra, eliminando a possibilidade de não existir mais vida.

Com a tecnologia ganhando mais força com o passar dos anos, ideias como Clonagem, por exemplo, já não seriam mais meros sonhos, e isso poderia acarretar problemas inimagináveis. Para os leigos, isso seria algo futurístico incrível, mas os benefícios não se comparam aos malefícios que podem gerar para a sociedade, nesse ponto e em busca de ajudar a bioética veio proporcionar uma reflexão entre as disciplinas (robótica, nanotecnologia, biogenética), trazendo a humanização e o debate da viabilidade da utilização destes novos recursos, a fim de uso consciente dos mesmos, sem prejudicar de forma rigorosa nosso meio e a nós mesmos.

O controle biológico do homem, especialmente o controle genético levanta questões éticas de gênero completamente novo, ao qual nem a prática nem a teoria precedente nos tem preparado. Uma vez que colocamos em discussão nada menos que a natureza e a imagem do homem, a prudência torna-se o nosso primeiro dever ético, e um argumento hipotético de nossa primeira responsabilidade. Refletir sobre as consequências antes de tomar as iniciativas não é outra coisa que uma norma de prudência. Nesse caso o bom senso sugere como fazer uso de nossa capacidade antes que estejamos prontos para usá-la. (JONAS, apud, ZANCANARO, 1998, p, 67).

É importante observar que, mesmo com todos os benefícios advindos da tecnologia, da ciência, é necessário acompanharmos de perto seus avanços e suas promessas futuras pois deixar o futuro da humanidade apenas em suas mãos sem que haja um princípio norteador de suas ações, pode ser perigoso, pois interesses são mascarados. Jonas afirma que, 
O homem bom não é aquele que se tornou um homem bom, mas aquele que faz o bem em virtude do bem. O bem é a causa no mundo, na verdade, a causa do mundo. A moralidade jamais se pode considerar como um fim. (JONAS, 2006, p. 156).

A técnica possui um poder que pode ser utilizado para o bem assim como, se usado de forma errada, pode gerar prejuízos para a humanidade. Mas deve ficar claro que ainda temos domínio sobre ela e para que algo contrário não ocorra, especialmente se tratarmos dos experimentos com o objetivo de prolongamento da vida, da eugenia, é de suma importância uma ética reguladora de suas ações. "O desejo de dominação trabalha com o sonho de tomar em suas mãos o próprio desejo de evolução” (ZANCANARO, 1998, p.67).

\section{CONCLUSÃO}

É importante ressaltar que, a relevância do Princípio Responsabilidade orientada ao agir tecnológico e a ideia de um homem perante a tecnologia, são o foco deste trabalho. Jonas constata que, a ética tradicional e seus mandamentos de "Agir próximo" como a misericórdia, a fraternidade e a compaixão continuam válidos, porém essas não são mais suficientes para dar suporte ao agir tecnológico.

Com a entrada das ciências tecnológica, o ser humano deve se conscientizar dos riscos utópicos e ilimitados que a mesma inflige e, tomar medidas preventivas contra os abusos e poderes descomunais provocados por ela. A técnica, "deve ser vista como poder, podendo-se tornar perigosa em razão da sua aplicação no domínio humano, como na 'engenharia genética' e a possibilidade teórica de 'clonagem bumana', com suas 'modificações arbitrárias”' (ZANCANARO, 1998, p.67).

Nesse contexto de inovações, Jonas começou a refletir sobre a mudança que acarretaria toda essa avalanche de novidades. Assim, o filósofo começou sua formulação sobre uma nova ética que possibilitaria uma saída para diminuir os impactos causados pelas novas ciências e suas respectivas tecnologias. Jonas não iniciou seus estudos do nada, ele viveu em uma época onde o modernismo tecnológico estava iniciando com força total, não somente para o caminhar da sociedade, mas também para uma provável destruição de um futuro que não nos pertence, mas que temos o dever de preservar.

Jonas buscou exemplificar que tudo feito no hoje, reflete no nosso amanhã. No imperativo de Kant, diz "Aja de tal modo que a máxima de tua ação se converta em lei universal". Ao elaborar esse imperativo, Kant não estava preocupado com o agir tecnológico, 
pois Kant exalta o sujeito, a liberdade e a consciência da ação, sendo o seu mandatório formal e lógico. Mas Jonas diz, "Aja de tal modo que os efeitos de tua ação sejam compatíveis com a permanência de uma vida autêntica sobre a terra" (O PRINCÍPIO RESPONSABILIDADE: Ensaio de uma ética para a civilização tecnológica, 1979).

Por isso, devemos olhar a técnica não apenas com olhos de admiração, mas, principalmente, com olhos de desconfianças. É necessário pensarmos a ética da responsabilidade como algo urgente, antes que as futuras gerações tenham que pagar pelo mau uso da técnica no presente. Para Jonas,

O que a técnica produz não somente características da equipe técnica, os aparelhos, a maquinaria, os meio de intervenção no mundo, senão também os objetos de poder, ou seja, aquilo que o poder estender ou produzir: isso por sua vez, tem adicionado à ação humana capacidades inteiramente novas, que antes nem sequer estavam no círculo do poder humano e em grande parte nem no círculo dos desejos humanos. (JONAS, 2013, p, 279).

A preocupação com o poder advindo da técnica deve fazer parte, agora mais que antes, de todas as nossas reflexões. Especialmente porque seu uso associado ao poder e ganância humana tanto pode mudar definitivamente a constituição humana quanto pode dizimar sua existência e a de todo o planeta. 


\section{REFERÊNCIAS}

BATTESTIN, Cláudia. GHIGGI, Gomercindo. O Princípio Responsabilidade de Hans Jonas: Um princípio ético para os novos tempos. IN: Revista Thaumazein, Ano III, número 06, Santa Maria (Outubro de 2010), pp. 69-85.

JONAS, Hans. O Princípio Responsabilidade: ensaio de uma ética para uma civilização tecnológica. Rio de Janeiro: PUC Rio, 2006.

Memórias. Madrid: Losada, 2005.

Técnica, Medicina e Ética: sobre a prática do princípio responsabilidade. São Paulo: Paulus, 2013.

O princípio vida. Fundamentos para uma biologia filosófica. Trad. Carlos Almeida Pereira. Petrópolis, RJ: Vozes, 2004.

MIRANDA, Ângela. A ética da condição humana na era da civilização tecnológica. Às voltas com Heidegger e Jonas. Florianópolis: INTERthesis, vol. 6, n.1, p. 48-73, jan-jul. 2009.

NETO, Correia Wilson. Tecnologia e Responsabilidade em Hans Jonas. Universidade Estadual de Londrina. (monografia). Londrina 2011.

ROHREGGER, Roberto. Biologia Sintética, Um Olhar a partir do Pensamento de Hans Jonas. Pontifícia Universidade Católica do Paraná - PUCPR. Mestrado em Bioética Curitiba, Pr. Brasil.

ZANCANARO, Lourenço. O conceito da Responsabilidade em Hans Jonas. Tese (DOUTORADO EM EDUCAÇÃO) Faculdade da Educação, Universidade Estadual de Campinas, Campinas, 1998. 